\title{
Cultura visual y educación de la mirada: imágenes y alfabetización
}

Sergio Martínez Luna ${ }^{i}$

\section{Resumen}

La cultura visual contemporánea compromete los modos de relación con el mundo y los otros. Los sistemas tecnológicos de producción y consumo de imágenes demandan una aproximación crítica a la que la escuela no es ajena. El proceso educativo es afectado por estas transformaciones. Los media contemporáneos redefinen formas de legitimidad, de conocer, enseñar y relacionarse. Frente a los discursos que culpan al exceso de imágenes de la decadencia de la educación y la cultura, es más interesante reconocer a las imágenes en su dimensión experiencial y política. La noción de que la imagen es transparente provoca que los significados que porta pasen desapercibidos, como un currículum oculto. El artículo propone acercarse a esta realidad desde la idea de que la visualidad contemporánea no es esencialmente visual, porque está atravesada por el lenguaje y el resto de sentidos. Se subraya así la necesidad de una alfabetización visual y de una mirada crítica.

\section{Palabras clave}

Imagen, Cultura Visual, Proceso educativo, Alfabetización visual.

\begin{abstract}
Contemporary visual culture has a qualitative impact on the ways of relation with the world and the others. Systems of production and consumption of images demand a critical approach that school cannot ignore. Educational processes are affected by these transformations. Contemporary media redefine forms of legitimacy, knowing, teaching, and relating to others. There are discourses that attribute the blame for the decadence of education and culture to an excess of images. However, it makes more sense to acknowledge the mediating dimension of image and therefore to consider it as experiential and political. The notion that image is transparent results in the invisibility of the meanings and cultural repertoires that images hold, as a hidden curriculum. The paper suggests an approach to that question from the idea that contemporary visuality is not essentially visual, as long as it is crossed by language and the other senses. On that basis, the need for a visual literacy and a critical look is stressed.
\end{abstract}

\section{Keywords}

Image, Visual Culture, Education process, Visual literacy.

\section{Introducción}

Las imágenes han entrado en las aulas ${ }^{1}$. En consonancia con la expansión general de lo visual en las sociedades contemporáneas los procesos y las situaciones

\footnotetext{
${ }^{1}$ A lo largo del artículo me refiero de forma implícita y en general a la escuela, es decir, a la educación obligatoria. Sin embargo, esas aulas también son las de la educación superior. La universidad por supuesto no está libre, ni debe estarlo, del impacto de la cultura visual en sus metodologías de investigación, formas de transmisión y puesta en circulación del conocimiento, e incluso en su papel dentro de la sociedad. A partir del controvertido encaje de unos Estudios Visuales en la universidad, especialmente en el ámbito de las Humanidades, Stephen Melville (MELVILLE, 2004) medita sobre estas cuestiones. Un amplio panorama sobre el estado actual de las Humanidades -aunque centrado en la academia estadounidense- desde su cruce con las nuevas tecnologías (que yo considero
} 
educativas se ven atravesados por una multiplicidad de imágenes de toda índole. Si nos preocupa como educadores la articulación de los nuevos dispositivos tecnológicos con los procesos de enseñanza-aprendizaje debe tenerse presente el recordatorio de que aquellos son de forma sistemática configurados como dispositivos de producción y reproducción visual. La inclusión de mecanismos de visualización en una variedad de objetos cotidianos -con el teléfono móvil convertido en una terminal de consumo, producción y transmisión de imágenes, como ejemplo paradigmático- señala el alcance de estos desarrollos. Parece que todo avance tecnológico esté asociado a la capacidad de generar y poner en circulación imágenes. La ubicuidad de las pantallas en los mundos de vida contemporáneos apunta a una suerte de saturación mediática que no nos deja dejar de ver y que, en consecuencia, hace difícil la creación de momentos de reflexividad y análisis de las imágenes que nos rodean y acompañan diariamente. La obsesión comunicativa, la insaciable necesidad de estar conectados (y las ansiedades asociadas a la desconexión) apuntan a una modificación profunda de los vínculos sociales en las esferas del trabajo, la escuela, la familia, la amistad, o la política. La lógica de la pertenencia, una vez desgastadas las amplias figuras de legitimidad que la sostenían (nación, comunidad, clase...), da paso, según Marina Garcés, a una lógica de la conexión que sin cesar demanda ser renovada a través de la disponibilidad permanente y completa de cada uno de nosotros (GARCÉS, 2006). Los terrores contemporáneos se encarnan en la amenaza constante a quedar fuera de esa modalidad de inclusión engarzada en la conexión personal, acrítica y precaria. Estas nuevas formas de dominio se articulan con la proliferación de imágenes, pantallas e información.

Si las imágenes penetran en el aula lo hacen impulsadas por un conjunto de dispositivos técnicos en absoluto neutrales a través de los que se modelan las economías de los saberes y sus modelos pedagógicos, las formas de producción y transmisión de conocimiento, la producción y reproducción social, las matrices de relación con el mundo y con los otros. Si es necesario, como decía Walter Benjamin, pensar la técnica de una manera no técnica (si es que estamos comprometidos en efecto con alguna forma de pensamiento crítico), ¿no deberían ser las aulas un escenario crucial para ensayar semejante aproximación?, ¿no debería ser precisamente allí donde las imágenes y las tecnologías visuales tendrían que encontrarse con las exigencias y las promesas de una forma de enseñar y aprender atenta a desentrañar el modelado de las subjetividades y la socialidad que aquellas conllevan de manera aparentemente inocente e inevitable? La respuesta, si confiamos aún en las potencialidades de la educación para producir conocimiento y criticidad sobre el mundo que habitamos, será inmediatamente afirmativa. Y sin embargo es este un sí demasiado apresurado, al que apenas cabría agradecer su voluntarismo. Que la técnica no es neutral y que a partir de ello solo nos queda como educandos y educadores, como ciudadanos, el deber de aproximarnos a ella desde la reflexividad crítica significa en primer lugar evitar ese lugar común, tantas

conjugadas siempre en torno a lo visual) se encuentra en GOLD (2012). Alejandro Piscitelli (PISCITELLI, 2010) ofrece una propuesta reflexiva y estimulante desde la articulación entre conocimiento, educación, y nuevas tecnologías. 
veces repetido, que dice que la técnica no es buena ni mala, y que depende de los usos que le demos. Las preguntas arriba formuladas no se agotan en esta solución fácil. Con ella queda desenfocada una cuestión que, entre otras cosas, toca de lleno a las políticas y los procesos educativos, en la medida en que compromete a la configuración de los sujetos y a sus modos de experiencia, comunidad y relación. Trastocados por la aparición de comunidades virtuales y redes digitales los presupuestos de pertenencia y convivencia tradicionales ya no dan cuenta de cómo a través de aquellas se abordan las relaciones y la socialización. Nosotros mismos, nuestras capacidades de conocer y desear, imaginar y amar, violentar y perdonar, son resultado de mediaciones técnicas específicas que dibujan el perfil de un mundo y una época. Es en el esfuerzo por el conocimiento consciente de tal perfilaquel que nos da las posibilidades de modificar lo dado, en la medida en que este se reconoce como producto humano-donde cabría pensar que la educación, a todos los niveles, debería tener un papel central.

\section{Medio-ambientes y procesos educativos}

La técnica expresa una sociedad, definiendo las relaciones que se dan dentro de ella. La técnica es el lenguaje que hablan los objetos (BREA, 2002, p. 113). Este lenguaje está conjugado hoy por lo visual. Pero se ganaría poco explicando esa declinación visual, que compone en efecto una construcción visual de lo social, desde una perspectiva cuantitativa que da cuenta, para escandalizarse o felicitarse, de una proliferación y un exceso inéditos de las imágenes. Sucede más bien un cambio cualitativo en la condición contemporánea de lo figurativo, según el cual las imágenes están ganando una cierta independencia de las realidades de las que eran representación. Lo visual ya no es el medio transparente por el que se referencia un mundo, porque las imágenes, al ganar una eficacia performativa para construir realidades, han atraído hacia sí mismas los procesos de conocimiento y simbolización. Cuando se introducen en las aulas dispositivos electrónico-visuales como pizarras digitales, plataformas, ordenadores, tabletas, videojuegos, teléfonos, está penetrando en la escena de la educación la materialización técnica de un determinado régimen visual que, apoyado en la digitalización masiva de información, soportes y contenidos, presenta sus correspondientes modos de hacer, ver, conocer, mirar y ser mirado, ver y ser visto.

Existe entonces un encuentro, quizás un colapso, entre la cultura visual y lo que ha venido en llamarse cultura del aula. Es responsabilidad de una pedagogía crítica hacer de tal encuentro una ocasión para el aprendizaje mutuo en lo que toca no solo a los contenidos sino a la forma que estos son redefinidos al ser expuestos a 
través de las nuevas tecnologías, que a su vez reconfiguran las modalidades de atención, enseñanza y aprendizaje. Esto significa que la aparición en el aula de la cultura visual, con sus dispositivos técnicos, determinaciones y posibilidades, compromete de manera oblicua a los ámbitos básicos de la acción y la intervención educativa de manera transversal e interdisciplinar, recorriendo desde los procesos de construcción de la identidad y los modelos de convivencia a las formas de enseñar, aprender y compartir el conocimiento.

No cabe duda de que los nativos digitales "piensan y procesan la información de un modo significativamente distinto a sus predecesores" (PENSKY, 2010). Pero los media no solo componen unas matrices de comprensión y relación a las que se pueda acudir en un momento dado, como si los inmigrantes digitales- pongamos que aquí nos estamos refiriendo a los educadores- pudieran elegir a voluntad su condición según las circunstancias. Los media forman un medio-ambiente dentro del que, más o menos conscientemente, nos relacionamos cotidianamente con el mundo, entablamos conversaciones, o construimos nuestras identificaciones. Por eso, si tomamos el término de cultura del aula como "una atmósfera o una sensibilidad y como una energía que está relacionada con la oportunidad del niño o niña para el aprendizaje y el desarrollo social" (GIBBS, 1994, cit. en FETHERSTON, 2008 , p. 17) concluiremos que no es posible separar a esa atmósfera de las transformaciones que se producen en el exterior, si es que los límites entre el aula y el exterior pudieran dibujarse nítidamente. Cualquier estudio de lo que sucede en el aula contiene, de hecho, una pregunta por dónde situar los límites que posibilitan la descripción relevante de los fenómenos estudiados. Lo que llamamos contexto es más un problema que un marco ya resuelto dentro del que inscribir una descripción, una intervención, o una investigación (VELASCO, DÍAZ DE RADA, 2006, pp. 315-317). Las situaciones del aula son un aspecto parcial del conjunto tensiones, líneas de fuerza, condicionantes económicos, normativos, sociales y culturales, que afectan en el día a día a la escuela. La institución escolar es una entidad heterónoma, inscrita en una variedad de procesos socioculturales. En este sentido, estudiar esa entrada de las imágenes en el aula es entender las formas de construcción, apropiación o reproducción de la realidad de las culturas y las comunidades específicas donde -en constelaciones económicas, tecnológicas, culturales, generacionales, de género desiguales- se genera tal fenómeno.

Las nuevas ecologías mediáticas afectan diferencialmente entonces al conjunto del proceso educativo y a los pilares básicos sobre los que este quiere fundamentarse más allá del desarrollo de unos y otros saberes instrumentales. Se trata, en primer 
lugar, de comprender cómo la información visual genera significados teóricos, prácticos y sociales, y, de forma más amplia, cómo las imágenes median los mundos de vida. Surgirá entonces la pregunta por el cruce entre procesos de subjetivación y la producción y consumo de imágenes, por la constitución de un yo a través de la mirada y del encuentro con el otro. Aparecerá a partir de este escenario la cuestión (en realidad inseparable de la anterior) acerca de la capacidad de los imaginarios y las imágenes -en base a su carácter intersubjetivo- de producir socialidad y comunidad. Las imágenes siempre llevan inscritas la tensión entre la presencia y la ausencia del otro, ellas son el registro visible de las tareas de construcción de una identidad dentro del ámbito social. Y en consecuencia, ¿cómo no prestar entonces atención a que la personalidad, la identidad, la propiocepción, se construyen hoy a través de la mediación de un ojo técnico, de la mirada generada en la cámara, proyectada en las pantallas que nos rodean?, ¿y cómo aproximarse a los procesos de socialización, a los retos de la diversidad y la convivencia, sin atender al hecho de que en la actualidad estos están volcados sobre los dispositivos de conectividad, de exposición relacional de la vida propia, de puesta en circulación de los imaginarios, ofrecidos por una variedad de aplicaciones electrónicas y redes sociales? Tanto las estructuras académicas como las sociales que funcionan en el incierto límite del dentro/fuera del aula, del dentro/fuera de la institución escolar, están atravesadas por nuevas formas de relacionalidad instantánea, figuras de legitimación provisionales, imágenes, textos y voces que juegan a aparecer en los intersticios de la vida social, entre lo normativo y lo informal, entre lo preceptivo y lo lúdico.

Apenas nada se ganaría con tomar la propagación de lo visual y la ubicuidad de la imagen como un cambio cuantitativo, o como un signo de los tiempos que, simplemente, toca ahora asumir. La noción de cultura visual, en su sentido más fuerte, quiere señalar un giro más profundo en los modos de experiencia, representación y creación de la realidad. De acuerdo con ello el concepto toma una complejidad y un tono polémico, para empezar en lo referente a la supuesta novedad histórica de la expansión y la relevancia de las imágenes. En este sentido, tampoco resulta operativa la posición que entiende, alarmada, la circulación desatada de las imágenes como una recaída en la superstición y la pasividad, como la decadencia de las culturas modernas de las lectoescritura. Las imágenes han estado, por así decir, siempre ahí, y a la afirmación con la que abríamos el artículo cabría responder con la pregunta de si alguna vez las imágenes se habían ido. Podemos ir más lejos e invocar la célebre pregunta de Bruno Latour acerca de si alguna vez hemos sido modernos. ¿Fue la modernidad occidental realmente capaz 
de separar el conocimiento racional ligado a la lectura y la exposición reflexiva de los sujetos a los grandes logros civilizatorios de ese otro conocimiento figurativo basado en la experiencia sensual del mundo, relegado por aquel proyecto a una minoría de edad anclada en lo masivo y lo supersticioso?

\section{Visualidad sin esencia visual}

Pensemos en el concepto de Bildung, aportado por la Ilustración alemana. En el ámbito de las transformaciones educativas y pedagógicas de la Ilustración este concepto hacía referencia al cultivo de uno mismo a través del vínculo entre filosofía - el saber de saberes que iluminaba el resto de conocimientos con la luz de la razón- y la educación como proceso productor de sujetos racionales y autónomos. La articulación entre ambas instancias señalaba el camino de crecimiento personal y cultural, cuyo punto de llegada era la consolidación autoconsciente de la individualidad y la identidad, libremente cohesionadas con la sociedad y el estado. Bajo el influjo de Wilhelm von Humboldt tal proyecto ascendió a ideal educativo. Según el modelo pedagógico basado en la Bildung la adquisición del conocimiento es en sí misma un proceso $y$, por tanto, no es reducible a un producto. Los sujetos envueltos en este modelo educativo aprenden las reglas del pensamiento y del conocer, más que unos u otros contenidos del conocimiento positivo, a los que en todo caso accederá no mecánicamente, sino desde una perspectiva crítica y reflexiva. Así, pensamiento crítico y adquisición de conocimiento se convierten, interiorizados por los sujetos cultivados y ciudadanos, en actividades libres y autónomas (READINGS, 1996). Estos sujetos han querido ser formados en la exposición reflexiva al bien y la belleza, testigos ellos mismos del lento crecimiento que les lleva a alcanzar una individualidad autónoma y una ciudadanía, que como seres racionales, les corresponde de pleno derecho. A menudo tal proceso quedó paradigmáticamente ligado a la soledad del lector (casi siempre en masculino) que se asoma, a través de los lenguajes oral y escrito, a los grandes monumentos civilizatorios como ideales a los que es deseable y legítimo aspirar. El modelo dominante es aquí más el de la lectura y la escucha atenta que el de la imagen y la (supuesta) inmediatez de la vista. Sin embargo, el propio término Bildung contiene, como señalara Gadamer, trazas visuales, pues deriva parcialmente de las tradiciones místicas de imitación de la imagen de Dios: Bild es imagen, figura, y se sitúa cerca del sentido de copia (Nachbild) y modelo (Vorbild) (JAY, 2003, p. 215).

Pero se objetará enseguida que la vista juega un papel central en el desarrollo de la epistemología moderna, la cual, de hecho, puede caracterizarse como 
fundamentalmente ocularcéntrica. En efecto, el saber científico moderno se apoya en el distanciamiento visual que asegura la objetividad y la neutralidad de la observación. Desde el científico en su laboratorio al etnógrafo en el campo, la posición segura del observador distanciado está garantizada por esa mirada elevada que ofrece descripciones e interpretaciones objetivas. La desconfianza frente a ese ojo descarnado, normativamente incapaz de comprometerse con sus objetos de estudio, ha sido el blanco de fundamentadas críticas al proyecto moderno y sus epistemologías (DENZIN, 1997; JAY, 2008). No solo es que en el ojo observador se filtren los dogmas del positivismo, sino que, inscrito en la constelación del saber y del poder, a través del ver se ocultan las operaciones de construcción de los significados, se invisibiliza al sujeto enunciador, su inevitable implicación en los hechos observados. Así, las críticas a ese ojo científico descarnado se cruzan con caracterizaciones de la mirada como invasiva y vigilante, espectacular e inquisitiva. Una investigación basada en los poderes de la vista, no deja margen al investigador para implicarse en lo observado, como tampoco le permite reconocer los condicionantes de su observación, aquellos que le ubican por definición en la posición dominante de sujeto y dueño de la mirada.

Esta tensión moderna alrededor del sentido de la vista y del poder de las imágenes, que enfrenta posiciones iconófilas e iconoclastas es, con todo, menos contradictoria de lo que parece. Depende de un régimen de reparto de la sensibilidad y de las capacidades que es también un ordenamiento local e históricamente específico. Se puede entender como una cierta jerarquización de los sentidos en relación a los saberes y a las formas de conocimiento en la que la vista, gracias a las características atribuidas de objetividad e inmediatez, quedaría del lado de los saberes instrumentales, mientras que la escucha acogería más adecuadamente los procesos internos de crecimiento reflexivo del yo. Por su parte, el gusto, el olfato y el tacto quedan relegados a un segundo plano por permanecer demasiado anclados al cuerpo, individual y social, y por tanto poco capaces de guiar algún tipo de emancipación intelectual.

Puede considerarse que la cultura visual actual, el régimen escópico contemporáneo, ha trastocado esa división al invadir las imágenes y la capacidad de ver todas las formas de relación y de conocimiento de los otros y del mundo. Hoy estarían cumpliéndose con plenitud las derivas y los imperativos de lo que Guy Debord Ilamara la sociedad del espectáculo. Hay sin duda una hipertrofia visual articulada con los mandamientos que exponen a la totalidad del mundo como objeto y sujeto de consumo masivo. La realidad lo es - reducida, deponteciada - 
en la medida en que es dada a ver. A través de tal operación se desaloja lo que resulta intolerable para este mundo-imagen, a saber, que en el ajuste exacto entre imagen, capital y consumo penetre de algún modo la contradicción o el desacuerdo. Lo visual es el vehículo de formas de relación basadas en una coincidencia instantánea con el mundo en la que se pretende agotar la totalidad de sentido. El control sistemático del lenguaje, del conocimiento y de la socialización es hoy sobre todo visual y aquel se realiza y se impone principalmente en el consumo instantáneo, en tiempo real, de imagen determinado por las industrias de la comunicación y entretenimiento. Este consumo de signos, así como la imperiosa obligación de su exhibición inmediata, es lo que marca la tendencia a la estetización y la semiotización integral de las experiencias y de los mundos de vida. Declinación estética que es finalmente empobrecedora pues su única fuerza y sentido está dirigida a multiplicar el valor de mercado de las relaciones, de las cosas, de los aprendizajes, de las modalidades del estar juntos. La experiencia sensible ha quedado capturada dentro de una lógica de la estetización generalizada impuesta desde las industrias culturales. Si una de las potencialidades del arte era la de hacer comunidad, compartir la experiencia estética y participar de sus tensiones utópicas en su proyección a la vida, hoy se cumple tal propósito despojándolo de su alcance político, haciéndolo gravitar sobre la explotación comercial de lo afectivo. Lo que ves es lo que es, si no consumes no eres.

¿Son operativos ante semejante situación los discursos apocalípticos que culpan al exceso de imágenes una decadencia cultural y educativa? Sucede a menudo con las declaraciones iconoclastas que su condena integral de lo visual -adoptando muchas veces un tono moral, si no moralizante- reproduce un esencialismo que dice que la experiencia de la imagen es siempre y únicamente visual, acotada a los potenciales y limitaciones del sentido de la vista. Ya hemos señalado cómo en el concepto de Bildung, aunque inclinado expresamente al lenguaje oral y escrito, habitan huellas visuales. Es que, si queremos acercarnos críticamente a la cultura visual, debemos tener en cuenta la complejidad y hasta la negatividad de ambos términos. Y, de este modo, entender el término visual como "impuro, sinestésico, discursivo, pragmático; y el de cultura como variable, diferencial, localizado entre zonas culturales y puesto en acción mediante prácticas de poder y resistencia" (BAL, 2004, p. 33).

Esta aproximación a la Cultura Visual se basa entonces en la idea de que todo ver es el resultado de una construcción cultural, articulada como un modo complejo e híbrido de construcción de los significados. Así que, aunque pueda parecer 
paradójico, es necesario partir del reconocimiento de que no hay algo así como una esencia de la visión. Hay más bien repartos diferenciales de las capacidades, jerarquizaciones contingentes de la sensibilidad, legitimaciones específicas de las multimodalidades de alfabetización, del conocer y del conocerse (DUNCUM, 2004), determinadas por cuestiones de poder, de género, culturales, económicas, institucionales. Como advierte W.J.T. Mitchell "no existen medios visuales" como tales, todos ellos implican de una forma u otra al resto de sentidos (MITCHELL, 2005). Ello abre la posibilidad, compleja, siempre atenta a unos u otros condicionantes, de construir - abandonando la condena en bloque de la visualidad como forma necesaria de embrutecimiento y control social - miradas e imágenes que no impliquen la objetivación y la minorización de lo observado. No todos los modelos de visualidad son totalizantes, cosificadores o panópticos: pueden abrirse a modos interrelacionales, intersubjetivos, de narración, conocimiento y experiencia, no replegados defensivamente sobre un ego imaginariamente clausurado en sí mismo. Es la posibilidad de mirar más allá - a través del esfuerzo por perfilar una mirada ética, componiendo algo así como una visualidad menorde los mandatos del ego y de los modos de identificación normativos y naturalizados que ofrece la imaginería cultural dominante (SILVERMAN, 2009).

\section{Educación, mirada, imagen}

¿Cuál es entonces el reto aquí para las instituciones y procesos educativos? Si no hay que dejar de insistir en que estas cuestiones afectan transversalmente al conjunto de la educación, desde sus mismos pilares básicos y, de este modo, a todas las didácticas, querría ahora mencionar el ámbito en el cabría esperar que aquellas recibieran un tratamiento concreto y singular. Me refiero, sin entrar aquí en debates sobre denominación, a la educación artística, la didáctica de la expresión plástica, de las artes y de la cultura visual.

Esta didáctica se enfrenta, por así decir, en primera línea a los problemas hasta ahora planteados, en la medida en que debe ocuparse de estudiar las artes y una variedad de manifestaciones visuales. Lo que interesa es preguntarse si el planteamiento y la puesta en práctica de esta materia están a la altura de los retos y de la complejidad de la cultura visual. La forma en que habitualmente se imparte y la concepción que de ella se tiene en la institución escolar (desde los sistemas educativos y la administración a, muchas veces, los mismos profesores, pasando por las familias) perpetúa una serie de tópicos que no responden a las realidades y a las demandas de un mundo complejo que se dice, se experimenta y se reproduce en pantallas e imágenes. El tópico por excelencia, aquel con el que todos los 
maestros y profesores de este ámbito se han tropezado alguna vez, es que la educación artística es algo así como una parte de las manualidades. Oponerse a este lugar común no quiere decir descartar la experimentación con los procesos creativos que se hacen con las manos - al contrario, sigue siendo importante conocer y desarrollar una multiplicidad de procedimientos manuales, cuyo conocimiento incide en la comprensión de imágenes y objetos-, sino que el eje de esta didáctica se ha desplazado, empujado por las transformaciones de la cultura visual contemporánea. Según María Acaso, la enseñanza de las artes y la cultura visual es un área "relacionada con el conocimiento, con el intelecto, con los procesos mentales, y no sólo con los manuales, con enseñar a ver y a hacer con la cabeza y con las manos y no sólo enseñar a hacer con las manos"(ACASO, 2009, p. 17).

La idea de que la escuela y en concreto el escenario del aula se convierta en un refugio seguro frente a una proliferación de imágenes que amenaza con derrumbar y banalizar los modos de conocimiento y de información basados en las tradiciones de la lectoescritura, no solo es criticable por ser poco o nada operativa. Como ha señalado Kerry Freedman (FREEDMAN, 2006) la cultura visual puede ser a la vez beneficiosa y perjudicial, segura y peligrosa, creativa y destructiva, pero, en todo caso, poco se gana adoptando una postura de protección de los alumnos frente a ella. En la misma línea, Marilda de Oliveira (OLIVEIRA, 2009) advierte que el estudio de la cultura visual posibilita aperturas, nuevas formas de ejercer la crítica y revisar viejos modelos de análisis y práctica de lo visual. En consecuencia, es más responsable proporcionar a los estudiantes las herramientas críticas para conocer la multiplicidad de significados, fuerzas, intereses y promesas que contienen las imágenes y los sistemas de representación, complejidad con la que inevitablemente aquellos conviven fuera ( $y$ dentro) de la escuela. Aun si esa posición protectora frente a la cultura visual pueda tomarse como bienintencionada, no deja de filtrarse en ella un poderoso currículum oculto que acaba dejando a los alumnos y alumnas (y me temo que también a los docentes) inermes frente a un reparto de los significados y de los valores, de los cuerpos y las sensibilidades, que es todo menos natural, por mucho que - precisamente a través de las manipulaciones de los imaginarios y la imaginería y sus materializaciones técnicas- se repita sin cesar que en él se agota la realidad.

Deberíamos preguntarnos a qué llamamos sociedad del espectáculo, término proveniente, como ya se mencionó, del devastador diagnóstico que Guy Debord hizo del orden socioeconómico nacido de la posguerra, en el que llegó a un punto 
de no retorno la fetichización de la mercancía, cumpliéndose en el espectáculo la disolución del ser en el tener y del tener en el aparentar (DEBORD, 2003). Hoy, obviando la filiación marxista del análisis del situacionista francés, la noción de espectáculo sirve al viejo humanismo liberal para adjetivar peyorativamente un mundo cuya decadencia se liga al ascenso de la imagen. Pero la denigración en bruto de la imagen, que tanto sigue debiendo a la condena platónica, reproduce en negativo el monólogo del mercado que hoy en efecto aquella encarna. Si desde la educación artística no se propone una aproximación crítica a la imagen tanto esta como los centros docentes en general "se convierten en los mejores aliados del hiperdesarrollo del lenguaje visual" (ACASO, 2009, p. 40). Es necesario cuestionar ese currículum oculto que, al pretender ignorar la presencia de las imágenes y los dispositivos visuales en el aula, contribuye a su recepción, utilización y reproducción irreflexivas.

Al hilo de esto cabe pensar si no será más bien que, en la confusión entre lo real y la apariencia, es esta última la que sale perdiendo. La apariencia es, señala Jacques Rancière, esa "realidad construida, esa realidad complementaria que hace que la realidad esté perdiendo el orden necesario de las cosas, que se vuelva problemática, abierta a la elección, al conflicto" (RANCIÈRE, 2011, pp. 56-57). Si lo que aquí queda rechazado es la apariencia, estaríamos viviendo, todavía con Rancière, no en una sociedad del espectáculo que olvida la realidad, sino en una "sociedad del cartel" que encadena a aquella a la tarea de sostener un único discurso, a legitimar un único régimen de la mirada, de los significados, de la sensibilidad. Liberar a las apariencias. ¿No sería entonces este el propósito de una teoría y una práctica de la imagen, de una pedagogía crítica de la imagen? ¿Y qué pasa (qué podemos) cuando entendemos que la escuela y la educación con tanta frecuencia no hacen sino sostener ese cartel, es decir, acomodar las imágenes a los órdenes de verdad ya dados?

Hay que preguntarse entonces en qué consiste hoy una educación de la mirada y una alfabetización visual. Las lamentaciones que ligan la decadencia de la educación a la invasión de imágenes y dispositivos visuales olvidan que la escuela siempre ha practicado una determinada política de lo visible a través de una multiplicidad de marcadores y retóricas visuales, desde la distribución de objetos y cuerpos, a los códigos del cuidado de la imagen personal y la vestimenta, pasando por los mapas, los esquemas, la arquitectura de los centros o el mobiliario. Lo que hemos heredado de la pedagogía moderna es el saber implícito que dice que en las formas visuales y en los actos de ver no existe opacidad ni mediación alguna, y 
que, por tanto, a través de ellos se obtiene un conocimiento directo y natural de la realidad (DUSSEL, 2009). Así que el objetivo central de la educación y la alfabetización visual sería el de dar a las imágenes consistencia como, a la vez, mediadoras y creadoras de realidad - portadoras de posiciones discursivas que contribuyen a pensar y experimentar el mundo (HERNÁNDEZ, 2007) -, determinadas por una cierta declinación técnica, por un sistema de la representación que habrá de hacerse explícito, considerado él mismo como representación.

La alfabetización visual recoge la idea de que las imágenes pueden ser leídas y que el significado puede ser elaborado y comunicado a través de actos de lectura, y así, se refiere a la capacidad para entender, interpretar y evaluar mensajes visuales (BAKER, 2012). Es una afirmación común que, contra lo que pueda parecer, solo se acerca parcialmente al propósito de una aproximación crítica a lo visual en el sentido arriba expresado. Se da un paso importante sin duda cuando las imágenes son consideradas como textos, ya que se introduce en la idea de que poseen y producen significados y que, en consecuencia, demandan un esfuerzo analítico de lectura. Los motivos, colores, líneas, puntos, tratamientos de la luz, texturas, producen significado y, por tanto, forma y significado no pueden quedar separados. Así como los textos, las imágenes no generan significado de forma inmediata, no son trasparentes, son medios y mediaciones inscritos en un determinado orden representativo, que deben ser abordadas a través de la lectura y, podría añadirse, de la escritura ${ }^{2}$. Pero la imagen no es algo que se pueda reducir al lenguaje por analogía, ni mucho menos es la mera ilustración de un texto, de unas palabras a las que deba alguna sumisión. Penetra a través de dicha analogía la pretensión de ubicar al texto o al lenguaje como elementos clave de un metalenguaje de la representación. Michel Foucault caracterizó el incierto territorio entre las palabras y las imágenes como una suerte de tierra de nadie, si bien muy transitada, que a la vez era el escenario de una batalla interminable entre formas de designar y describir, modelar el conocimiento y determinar sus alianzas con el poder, es decir, el escenario donde se componen y van estratificando distintas epistemes (FOUCAULT, 1981) $)^{3}$. Según esto, una inteligencia figurativa sabrá reconocer que unos u otros metalenguajes están formados a su vez por una "serie de figuras e

\footnotetext{
${ }^{2}$ Como advierte W.J.T. Mitchell (MITCHELL, 2009, p. 104), si tomamos de forma literal la expresión "lenguaje visual" nos encontramos con el punto en el que el ver y el hablar, la pintura (picture) y la impresión convergen en un medio que llamamos escritura.

${ }^{3} Y$ véanse las reflexiones de W.J.T. Mitchell (MITCHELL, 2009, pp. 63-69) sobre las relaciones entre palabras e imágenes en Foucault.
} 
imágenes que en sí mismas deben ser analizadas" (MITCHELL, 2009, p. 22). El de texto es entonces un concepto que sostiene, y no concilia, la tensión entre imagen y lenguaje. Es ese momento crítico y controvertido de los conceptos el que resulta más productivo (BAL, 2009, pp. 40-41). Si la imagen no puede quedar subsumida al lenguaje, se encuentra no obstante en él la vía para oponerse a la lógica del significado autoevidente de lo visual que lo deja blindado frente al análisis. Y si hay una dimensión textual o lingüística en la visión, del mismo modo existe una visual en los actos de lectura y escritura. Es alrededor de estas tensiones donde la educación visual encara unos retos que en primer lugar cuestionan la estabilidad y las delimitaciones disciplinarias de unos u otros planteamientos didácticos, institucionales, curriculares, teóricos. En su encuentro, las fronteras identitarias entre imágenes y las palabras entran en crisis: la escritura se expone, la imagen habla. Los dispositivos y las formas interfaz, cuya organización de la comunicación, la atención y el conocimiento, impregna ya no solo nuestra aproximación instrumental a todo tipo de soportes (desde los libros al televisor, desde la pizarra digital a la consola), sino que se compone ya en un auténtico modelo mental, ejemplifican esto de manera inmejorable (CATALÁ DOMENECH, 2010).

\section{Conclusión (Tocar las imágenes)}

El medio-ambiente visual puja por su propia invisibilidad en la esfera pública contemporánea. Más que convivir con las imágenes convivimos con la idea implícita de que estas son un medio invisible que facilita la transmisión fluida de los significados y que asegura las formas de subjetividad e identificación dominantes. Se convive con ellas porque no molestan, "no perturban un sistema de relaciones que, por el contrario, consolidan con su presencia" (CRUZ SÁNCHEZ, 2010, p. 10). Y sin embargo, la imagen contemporánea, la imaginería digital y los dispositivos técnicos que la producen y la ponen en circulación contienen la promesa de una experiencia de la esfera pública más disensual y menos obsesionada con el apaciguamiento social. Contienen, en primer lugar, la posibilidad de una desestabilización de los repartos de la sensibilidad y de las capacidades. Hacen posible imaginar una esfera pública formada por ciudadanos informados y conscientes del uso social de los medios, desbaratando por tanto la impuesta asignación de actividad y pasividad entre, respectivamente, productores y consumidores, actores y espectadores. Es hacia ese escenario a donde se ha desplazado la promesa emancipatoria que sigue habitando en la educación artística. Por otro lado, la visualidad contemporánea no es eminentemente visual, sino que desordena las jerarquizaciones de lo sensible. Es más táctil, háptica, que esencialmente visual, y a partir de ahí se redefine el conjunto de las actividades 
perceptivas en un sentido intersensorial (PÉREZ TORNERO, 2008). Si las imágenes se tocan, deberían también ellas tocar, dejar sentir su presencia intimidante, propiciadora, polémica, en nuestras relaciones con los otros y con el mundo, atreviéndonos a ir más allá de una interconectividad banalizada para explorar nuevos experimentos existenciales, educativos y políticos.

Podría muy bien declararse que hoy podemos tocar las imágenes. Pero entonces ya no se trataría solo de la posibilidad de re-tocar, hacer y consumir objetos, informaciones o mentiras visuales, sino de convivir, soñar, desear, conocer, sufrir, con las imágenes. Pero ¿quién es el "nosotros" de esa declaración? ¿A qué comunidad cultural, de edad, de género, de interés, afectiva, discursiva, hace referencia o se compone a través de ella? E intuyo que podría entenderse ese "tocar las imágenes" también en el sentido musical, en el de componer partituras según las que se interpretarán los conflictos, las amistades, las frustraciones, los amores y los anhelos. Educar la mirada significa no solo aprender a leer las imágenes, sino que, a partir de la complejidad de los actos de lectura/visión, la mirada se disponga al esfuerzo por transformar las imágenes y los repertorios de identificación y diferenciación normativos que en ellas se afirman.

\section{Referencias}

ACASO, María. La educación artística no son manualidades. Madrid: Catarata, 2009.

BAKER. Frank. Media Literacy in the K-12 Classroom. Philadelphia: ISTE, 2012. BAL, Mieke. El esencialismo visual y el objeto de los Estudios Visuales. Estudios Visuales, 2, 2004, pp. 11-49

BAL, Mieke. Conceptos viajeros en las Humanidades. Murcia: Cendeac, 2009.

BREA, José Luis. La era postmedia. Salamanca: Centro de Arte de Salamanca, 2002.

CATALÁ DOMENECH, Josep Maria. La imagen interfaz. Representación audiovisual y conocimiento en la era de la complejidad. País Vasco: Universidad del País Vasco, 2010.

CRUZ SÁNCHEZ, Pedro Antonio. Ob-scenas. La redefinición política de la imagen. Murcia: Nausícaä, 2010.

DEBORD, Guy. La sociedad del espectáculo. Valencia: Pre-Textos, 2003.

DENZIN, Norman. Interpretative Ethnography. California: Sage, 1997.

DUNCUM, Paul. Visual Culture Isn't Visual: Multiliteracy, Multimodality and Meaning, Studies in Art Education, 45, 3, 2004, pp. 252-264. 
DUSSEL, Inés. Escuela y cultura de la imagen: nuevos desafíos. Nómadas. Universidad Central de Colombia, 30, 2009, pp. 180-193.

FETHERSTON, Tony. Visual Culture in the Classroom. Australian Journal of Teacher Education, 33, 3, 2008, pp. 16-30.

FOUCAULT, Michel. Esto no es una pipa. Ensayo sobre Magritte. Barcelona: Anagrama, 1981

FREEDMAN, Kerry. Enseñar la Cultura Visual. Barcelona: Octaedro, 2006.

GARCÉS, Marina. Encarnar la crítica. EIPCP, 2006, disponible en: http://eipcp.net/transversal/0806/garces/es) (09-09-2014)

GIBBS, Jeanne. Tribes: A new way of learning and being together. New York: Centre Source Systems, 1994.

GOLD, M.K. (Ed.) Debates in Digital Humanities. Minneapolis: University of Minnesota Press, 2012.

HERNÁNDEZ, Fernando. Espigador@s de la Cultura Visual. Otra narrativa para la educación de las artes visuales. Barcelona: Octaedro, 2007.

JAY, Martin. Campos de fuerza. Barcelona: Paidós, 2003.

JAY. Martin. Ojos abatidos. Madrid: Akal, 2008.

MELVILLE, Stephen. Giro entre las ruinas. Estudios Visuales, 2, 2004, pp. 109121.

MITCHELL, W.J.T. No existen medios visuales. En: BREA, J.L. (ed.) Estudios Visuales. La epistemología de la visualidad en la era de la globalización. Madrid: Akal, 2005, pp. 17-25.

MITCHELL, W.J.T. Teoría de la imagen. Madrid: Akal, 2009.

OLIVEIRA, Marilda Oliveira de. O papel da Cultura Visual na formação inicial em Artes Visuais. En: MARTINS, R., TOURINHO, I. (eds.) Educação na Cultura Visual, narrativas de ensino e pesquisa. Santa Maria: U.F.S.M., 2009. pp.213224.

PENSKY, Marc (2010). Nativos e Inmigrantes Digitales. Cuadernos SEK 2.0., 2010, disponible en:

http://www.marcprensky.com/writing/PrenskyNATIVOS\%20E\%20INMIGRANTES\%2 ODIGITALES\%20(SEK).pdf) (20-07-2014)

PÉREZ TORNERO, José Manuel. La sociedad multipantallas: retos para la alfabetización mediática. Comunicar, 31, XVI, 2008, pp. 15-25.

PISCITELLI, Alejandro. EI Proyecto Facebook y la Postuniversidad. Sistemas operativos sociales y entornos de aprendizaje. Barcelona: Ariel, 2010.

RANCIÈRE, Jacques. Momentos políticos. Buenos Aires: Capital Intelectual, 2011.

READINGS, Bill. The University in Ruins. Harvard: Harvard University Press. 1996.

SILVERMAN, Kaja. El umbral del mundo visible. Madrid: Akal, 2009. 
VELASCO, Honorio, DÍAZ DE RADA, Ángel. Lecturas de Antropología para educadores. Madrid: Trotta. 2006.

i Doctor en Humanidades Universidad Carlos III de Madrid. Profesor Universidad Camilo José Cela de Madrid. Facultad de Educación y Ciencias Sociales. Participa en el Proyecto de Investigación: Culturas Materiales, Culturas Epistémicas. Estándares, Prácticas cognitivas y conocimiento. Universidad Autónoma de Madrid. E.mail: sergiomluna@hotmail.com

Recebido em 19/11/2014

Aprovado em 15/12/2014 